\title{
Select Ethical Aspects of Next-Generation Sequencing Tests for Newborn Screening and Diagnostic Evaluation of Critically Ill Newborns
}

\author{
Kuntal Sen ${ }^{1}$, Jennifer Harmon ${ }^{2}$ and Andrea L. Gropman ${ }^{1, *(D)}$ \\ 1 Division of Neurogenetics and Developmental Pediatrics, Center for Neuroscience and Behavioral Medicine, \\ Children's National Hospital, Washington, DC 20010, USA; ksen2@childrensnational.org \\ 2 Rare Disease Institute, Children's National Hospital, Washington, DC 20010, USA; \\ jharmon2@childrensnational.org \\ * Correspondence: agropman@childrensnational.org; Tel.: +1-202-476-3511; Fax: +1-202-476-4336
}

check for updates

Citation: Sen, K.; Harmon, J.; Gropman, A.L. Select Ethical Aspects of Next-Generation Sequencing Tests for Newborn Screening and

Diagnostic Evaluation of Critically Ill Newborns. Int. J. Neonatal Screen. 2021, 7, 76. https://doi.org/10.3390/ ijns7040076

Academic Editors: Lynn Wein Bush and Olaf Bodamer

Received: 25 August 2021

Accepted: 4 November 2021

Published: 8 November 2021

Publisher's Note: MDPI stays neutral with regard to jurisdictional claims in published maps and institutional affiliations.

Copyright: (c) 2021 by the authors. Licensee MDPI, Basel, Switzerland. This article is an open access article distributed under the terms and conditions of the Creative Commons Attribution (CC BY) license (https:// creativecommons.org/licenses/by/ $4.0 /)$.

\begin{abstract}
In this review, we analyze medical and select ethical aspects of the increasing use of nextgeneration sequencing (NGS) based tests in newborn medicine. In the last five years, there have been several studies exploring the role of rapid exome sequencing (ES) and genome sequencing (GS) in critically ill newborns. While the advantages include a high diagnostic yield with potential changes in interventions, there have been ethical dilemmas surrounding consent, information about adult-onset diseases and resolution of variants of uncertain significance. Another active area of research includes a cohort of studies funded under Newborn Sequencing in Genomic Medicine and Public Health pertaining to the use of ES and GS in newborn screening (NBS). While these techniques may allow for screening for several genetic disorders that do not have a detectable biochemical marker, the high costs and long turnaround times of these tests are barriers in their utilization as public health screening tests. Discordant results between conventional NBS and ES-based NBS, as well as challenges with consent, are other potential pitfalls of this approach. Please see the Bush, $\mathrm{Al}-\mathrm{Hertani}$ and Bodamer article in this Special Issue for the broader scope and further discussion.
\end{abstract}

Keywords: critically ill newborns; ethics; genomic sequencing; newborn screening; policy; rapid whole exome sequencing; rapid whole genome sequencing

\section{Introduction}

With the rapid evolution of molecular genetics, next-generation sequencing (NGS) testing methods such as exome sequencing (ES) and genome sequencing (GS) are being increasingly used for diagnostic evaluation of critically ill infants as well as for newborn screening (NBS) [1-3]. They have been applauded for the promise they hold for the prompt and precise diagnosis of pre-symptomatic as well as sick infants. However, there are several psychosocial and ethical dilemmas surrounding the use of these tests under these circumstances that require discussion. Many of these issues have been historically associated with ES and GS, in general; however, other challenges are unique regarding their use in neonatal medicine.

\section{Next-Generation Sequencing for Newborn Screening}

In the past few years, there have been several studies by various groups to explore the use of NGS-based tests such as ES and GS for NBS. While these techniques may enable clinicians to screen for rare diseases that do not have any reliable biochemical markers, there are several moral caveats to be considered. [1,2,4].

NBS was designed as a universal cost-effective screening test aimed at early detection of treatable hereditary (and a few non-hereditary) conditions to prevent long-term mortality and morbidity [5]. The test utilizes dried blood spots from heel prick samples 
obtained typically on day one of life. The test screens for an array of monogenic inborn errors of metabolism (IEM), in addition to endocrine disorders, hemoglobinopathies and immunodeficiency syndromes [6]. The Advisory Committee on Hereditary Disorders in Newborns and Children (ACHDNC) makes recommendations to the individual states I the USA regarding potential new disorders to be added to the NBS. Currently, there are 35 core and 26 secondary conditions on the recommended uniform screening panel (RUSP). The American College of Medical Genetics publishes action sheets (or ACT sheets) for positive screens, to provide uniform practice guidelines for pediatricians, neonatologists and biochemical geneticists [7]. Some conditions which may present with metabolic crisis (e.g., organic acidemia) and warrant prompt evaluation in an inpatient setting, whereas others with insidious onset (e.g., phenylketonuria) are followed up in an outpatient setting.

Robert Guthrie devoted several years to developing the first screening test utilizing the bacterial inhibition assay for phenylketonuria [8]. The NBS is often referred to as 'the PKU test,' which remains a testimony to his career. The introduction of tandem mass spectrometry (MS/MS) revolutionized the landscape of NBS as the technique allowed screening for many disorders due to its ability to measure several analytes (plasma amino acids and the acylcarnitine profile) simultaneously [9]. The testing laboratories utilize national databases to determine the cut-off values for analytes and sometimes may involve second-tier tests. In the last decade, with the discovery of novel therapies, other disorders including storage diseases, $\mathrm{X}$-linked adrenoleukodystrophy (X-ALD) and spinal muscular atrophy have been included in the RUSP for several states, which use different technologies for the screening test [10-14]. The literature suggests that screening for X-ALD poses a plethora of dilemmas, and there have been ongoing modifications to the follow-up protocol. The challenges include establishing contact with other family members across different generations who may be affected based on an X-linked inheritance pattern, and care co-ordination with sequential neuroimaging to identify those who will develop the cerebral form of the disease [15]. Massively parallel sequencing such as ES and GS has been used abundantly for diagnostic evaluation of pediatric genetic diseases, and clinical researchers finally decided to interrogate its potential for NBS [14]. The National Human Genome Research Institute funded a cohort of studies to evaluate the medical, economic and psychosocial effects of integrating exome sequencing (ES) for NBS, which led to the formation of Newborn Sequencing in Genomic Medicine and Public Health.

North Carolina Newborn Exome Sequencing for Universal Screening (NC NEXUS) enrolled 106 newborns and children with previously diagnosed metabolic diseases and hearing loss, and ES results confirmed an underlying diagnosis in $88 \%$ and $18 \%$ of the patients, respectively. The results included pathogenic variants in hereditary cancer syndromes in two children, and 1.8 variants per patient showing a carrier status for recessive conditions [1]. The BabySeq Project is another noteworthy study from this cohort. The group enrolled and randomized half of the families of newborns from Brigham Women's Hospital and Boston Children's Hospital to receive ES-based NBS. Out of 159 newborns enrolled, 15 were found to be at risk of childhood-onset conditions. Risk of adult-onset diseases, a carrier status and pharmacogenomic variants were detected in $3.5 \%, 88 \%$ and $5 \%$ of subjects, respectively. Testing parental samples resulted in interpretation of variants in $8 \%$ of cases [2,4].

Utilization of ES-based NBS is advantageous as it allows for screening of several monogenic conditions that do not have a consistent analyte that can be measured using MS/MS. For instance, mitochondrial disorders and proximal urea cycle disorders have historically been impossible to screen, despite the availability of therapies and interventions $[16,17]$. ES-based NBS could also shorten the diagnostic odysseys for those genetic diseases where there is no precise treatment, but where early diagnosis can have a significant impact on the medical care and parental perspectives. However, this rationale defies the very ethos of the Wilson and Jungner criteria, which emphasize the actionability of the disorder and cost-effectiveness of the test as the core principles of NBS [18]. The high costs and long turnaround times of NGS are obvious barriers in the current scenario, which hinder its 
integration as a widespread public health screening test [6]. There are also studies that suggest that the results of conventional NBS and ES-based NBS may be discordant, and the latter alone may not very specific in screening for IEM $[19,20]$.

While shortening the diagnostic journey for infants who are sick can substantially change family's viewpoints, diagnosis of childhood-onset conditions and carrier status can cause untold and unwarranted anxiety $[1,3,4]$. The BabySeq project did include an option to disclose the results of adult-onset conditions and applied a post-consent survey to better delineate parental perspectives [2]. NBS has always been an 'opt out' rather than an 'opt in' test, where families are required to actively decline it if they do not wish for their newborn to receive it. This is based on the dramatic success of the program, which has led to the slogan "newborn screening saves lives." Parents often do not understand the purpose and process of NBS. If ES or GS were ever to become a standardized screening tool, the consenting process would need to be robust and standardized, as was proposed in the pilot studies. Reporting and resolution of variants of uncertain significance may pose several challenges for the molecular genetics laboratories as well as the clinical teams following up with these families [21]. The follow-up testing and clinic visits secondary to unclear results have been known to cause substantial financial and psychological strain for families even with the conventional NBS, and this can only be accentuated with the incorporation of ES-based NBS, unless meticulous consent and education can be ensured [2,6,22,23]. As per recommendations from the Pediatric Task Force of the Global Alliance for Genomics and Health, each jurisdiction needs to resolve ethical and policy issues regarding the disclosure of incidental or secondary findings to families, as well as the ownership, appropriate storage and sharing of genomic data. Ultimately, the best interests of children should form the basis of all decisions [21]. Since medical geneticists, genetic counsellors and metabolic dietitians are still a small group, such a drastic upgrade in NBS may also cause disruption to the access to and uniformity of care [24].

\section{Next-Generation Sequencing for Diagnostic Evaluation of Critically Ill Newborns}

While the newborn screening programs and the BabySeq project have focused on predicting and preventing future disease in pre-symptomatic infants with genetic disorders, another active area of investigation has focused on the use of rapid genomic sequencing techniques in the evaluation of critically ill infants.

Studies have estimated that genetic diseases are present in approximately $16 \%$ of neonates in regional ICUs; furthermore, there is high mortality in infants with genetic diseases, which accounts for an estimated $20 \%$ of deaths in this age group, and in one center, accounted for an estimated $45 \%$ of neonatal intensive care unit (NICU) deaths over a ten-year period $[25,26]$. It is proposed that the primary benefits of early genetic diagnosis in these patients include both the rapid implementation of targeted interventions that may decrease morbidity, as well as the rapid identification of likely futile intensive care in the course of what may otherwise be a protracted diagnostic approach during, which parents may experience "inappropriate hope" or "needless guilt." Meanwhile, secondary benefits may include guiding parents regarding the risk of recurrence in future children as well as possible overall healthcare cost reductions [1,27].

Since 2015, several studies have sought to investigate the clinical utility of genomic sequencing in the NICU setting (Table 1). In these studies, the percentage of patients receiving a genetic diagnosis as a result of NGS has ranged from 21 to $57 \%$, with results returned in a range of 2.3 to 95 days and the majority of studies utilizing rapid exome or genome sequencing and returning the results in fewer than 21 days (Table 2) [28-34]. Comparatively, a retrospective study comparing the diagnostic yield of genomic testing showed similar diagnostic sensitivity of rapid whole genome sequencing (rWGS), with $43 \%$ of infants receiving a genetic diagnosis compared to only $10 \%$ diagnostic sensitivity in infants who underwent a standard genetic testing protocol; similarly, another research group obtained a genetic diagnosis for $8 / 20$ critically ill newborns using a targeted gene panel approach based on phenotypic presentation, and was able to obtain a genetic diag- 
nosis for an additional five patients when whole exome sequencing (WES) was offered to those patients with a negative gene panel [35,36]. Interestingly, one study showed that the phenotype of neonates was a poor predictor of the underlying genotype in $90 \%$ of patients evaluated in the ICU setting with WGS, suggesting that standard genetic evaluation would likely delay the diagnosis for the majority of these critically ill patients [31]. These conclusions were supported by the results of the NSIGHT2 trial, in which a subset of patients was selected to receive ultrarapid whole genome sequencing (urWGS) as a first-tier diagnostic; in general, these patients were more unstable and had differential diagnoses that included rare disorders requiring specific targeted therapies to prevent morbidity and mortality [34]. While urWGS was more costly than the other testing modalities (rWES and rWGS) evaluated in this study, the percentage of patients that received a genetic diagnosis was significantly greater in the urWGS cohort, with a similarly greater proportion of infants in that group receiving a diagnosis for which immediate intervention was available [33].

Table 1. Summary of studies investigating clinical feasibility and utility of NGS in critically ill neonates.

\begin{tabular}{|c|c|c|c|c|c|}
\hline Authors & $\begin{array}{c}\text { Year } \\
\text { Published }\end{array}$ & Study Design & Patient Location & Type of Test & Medium Turnaround Time \\
\hline Willig et al. & 2015 & Retrospective & NICU/PICU & Trio rWGS & 23 days \\
\hline Van Diemen et al. & 2017 & Prospective & $\begin{array}{l}\text { NICU / PICU } \\
\text { (Age < } 1 \text { year) }\end{array}$ & rWGS & 12 days \\
\hline Meng et al. & 2017 & Retrospective & NICU/PICU/CICU & $\begin{array}{c}\text { WES (proband } \\
\text { only/trio/rapid trio) }\end{array}$ & $\begin{array}{c}\text { Proband WES: } 95 \text { days } \\
\text { Trio WES: } 51 \text { days } \\
\text { rWES: } 13 \text { days }\end{array}$ \\
\hline French et al. & 2019 & Prospective & NICU/PICU & Trio rWGS & 27 days \\
\hline Elliott et al. & 2019 & Prospect & NICU & Trio rWES & 7.2 days * \\
\hline Kingsmore et al. & 2019 & $\mathrm{RCT}$ & NICU/PICU/CICU & urWGS/rWGS/rWES & $\begin{array}{l}\text { urWGS: } 2-3 \text { days } \\
\text { rWGS/rWES: } 11.8 \text { days }\end{array}$ \\
\hline Freed et al. & 2020 & Prospective & NICU/PICU/CICU & Trio rWES & 9 days \\
\hline
\end{tabular}

NICU, neonatal intensive care unit; PICU, pediatric intensive care unit; CICU, cardiac intensive care unit; WES, whole exome sequencing; WGS, whole genome sequencing; rWES, rapid whole exome sequencing; rWGS, rapid whole genome sequencing; urWGS, ultra-rapid whole genome sequencing, RCT, randomized clinical trial. * Time to preliminary results.

Table 2. Results of studies investigating clinical feasibility and utility of NGS in critically ill neonates.

\begin{tabular}{|c|c|c|c|c|c|}
\hline Authors & $\begin{array}{l}\text { Number of } \\
\text { Participants }\end{array}$ & Number of Diagnoses & $\begin{array}{l}\text { Number with } \\
\text { Changes in } \\
\text { Management }\end{array}$ & $\begin{array}{l}\text { Number with } \\
\text { Escalation of Care }\end{array}$ & $\begin{array}{c}\text { Number with } \\
\text { Limitation of Care }\end{array}$ \\
\hline Willig et al. & 35 & rWGS 20/35 (57\%) & 13 & 6 & 6 \\
\hline Van Diemen et al. & 23 & $7 / 23(30 \%)$ & Not reported & Not reported & Not reported \\
\hline Meng et al. & 278 & $\begin{array}{c}102(36.7 \%) \\
\text { Subset: rWES 32/63 (50.8\%) }\end{array}$ & $\begin{array}{c}53 \\
\text { Subset rWES: } 23 / 32\end{array}$ & 12 & 19 \\
\hline French et al. & 195 & $40(21 \%)$ & 12 & 5 & 7 \\
\hline Elliott et al. & 25 & $18(72 \%)$ & 15 & 4 & 3 \\
\hline Kingsmore et al. & 213 & $\begin{array}{c}49(24 \%) \\
\text { urWGS 11/24 }(46 \%) \\
\text { rWGS 18/94 }(19 \%) \\
\text { rWES } 19 / 95(20 \%)\end{array}$ & Not reported & Not reported & Not reported \\
\hline Freed et al. & 46 & $20(43 \%)$ & 24 & 5 & 5 \\
\hline
\end{tabular}

rWES, rapid whole exome sequencing; rWGS, rapid whole genome sequencing; urWGS, ultra-rapid whole genome sequencing.

The majority of these studies have quantified changes in management as a secondary measure and have shown repeatedly that these NGS results and subsequent genetic diagnoses have a direct impact on the decisions made by clinicians and families. These changes have encompassed both escalation in patient care (e.g., placement of a gastrotomy tube in a patient determined to have chronic feeding difficulties), as well as limitations in care (e.g., deferral of heart transplant in a patient expected to have a poor neurological 
prognosis) [28,30-32,34]. In addition to exploring the impact of rWES on acute ICU management, the most recent study reported by Freed et al. demonstrated the feasibility of implementing a rapid genomic sequencing protocol using a commercial send-out lab rather than an internal research-based testing platform, and included a full informed consent process with the option to receive secondary results [34]. As these studies have continued to consistently show a high yield of diagnoses contributing to alterations in management, and as commercial platforms have made these diagnostic modalities more accessible, a question has emerged: should rapid genomic sequencing be considered the standard of care for initial genetic diagnostic evaluation in critically ill infants? At the same time, a second question has also moved more clearly into focus: what are the ethical implications and challenges of utilizing genomic sequencing in the intensive care setting?

While the feasibility of rapid genomic sequencing for the timely diagnosis of suspected monogenic disorders in critically ill newborns has emerged only over the last decade, much accompanying literature over the same time period explores the potential technical and ethical concerns that may limit the widespread adoption of this testing approach. These include the current payer system that typically reimburses only outpatient genomic studies, the challenge of timely resolution of variants of unknown significance (VUS) and the possible impacts of rapid transition to genetic testing on parental anxiety and subsequent parent-infant bonding $[27,37]$. One of the most often and extensively discussed ethical concerns is the question of secondary findings, including the reporting of childhood-onset diseases not related to the patient's clinical presentation at the time of testing, and even more fraught, the reporting of adult-onset diseases. One case report in the literature from the BabySeq project highlights the moral distress felt by study researchers upon finding a $B R C A 2$ mutation in a male infant whose parents had not consented to receive information regarding adult-onset disease [38]. As a result of this moral distress, the research team approached the IRB for permission to re-consent the family to receive information regarding adult-onset disease. In this case, the study protocol was changed so as to enroll only families who would consent to receiving information about adult-onset diseases, so as to avoid further ethical dilemmas and subsequent moral distress for laboratory personnel who could ostensibly know information regarding an actionable disease with no recourse to provide that information to the person it most directly affected [38]. While some researchers have argued that testing for genetic susceptibilities to adult-onset diseases is a potential violation of the future autonomy of the infant who has undergone genomic testing, others have developed ethical models that consider the interests of the family as a unit, in which the wellbeing of the infant undergoing testing is dependent on the wellbeing of the family unit as a whole $[39,40]$. With the specific example of this child found to have a BRCA2 mutation, the potential impact of this autosomal, dominant adult-onset condition on the health and mortality of the child's affected parent was considered a threat to the wellbeing of the family unit, which posed a credible downstream threat to the patient's health as well $[40,41]$.

Another ethical consideration is access to these technologies, which is limited by several factors, including availability of in-house testing and the associated costs of genomic testing in the setting of uncertainty regarding the likelihood of insurance reimbursement for these testing strategies. Several studies have suggested that panel-based testing could prove a reasonable alternative strategy to accomplish rapid diagnosis in the ICU setting, with the proposed benefits of ensuring that a greater number of patients in need of these rapid diagnoses receive them, while also decreasing costs. In one study, a panel of 4503 genes was utilized for rapid evaluation of critically ill neonates; in the study, this panel-based approach yielded a diagnosis in $10 / 20(50 \%)$ cases and a partial diagnosis in an additional $1 / 20(5 \%)$ cases, similar to those results reported in the genomic sequencing studies referenced in Table 2 [42]. Furthermore, the panel-based approach cost $\$ 6000$ in this study compared to the $\sim \$ 16,000-\$ 17,500$ cost reported for rWGS in other studies [42]. Despite these encouraging results suggesting possible non-inferiority of the panel-based approach, issues may arise from inconsistencies in variant detection between two modalities; for 
example, the GEMINI study, which directly compared the results of a sequencing panel containing 1722 genes to rWGS, demonstrated discordance between the two platforms in $27 \%$ of diagnoses [43]. While many of these were due to technical differences between the platforms, generally stemming from the known inability of the sequencing panel to detect copy number variants, a number resulted from discordance in variant analysis both with respect to the algorithms used to detect and filter variants as well as the methods used to analyze the pathogenicity of detected variants [43]. These findings demonstrate that technical factors add an additional layer of complexity into this process, necessitating an even more nuanced consideration when balancing all the factors that may influence the utility of one diagnostic strategy over another, especially regarding the potentially extensive amount of data analysis required for interpretation of genomic sequencing compared to the inherently more focused datasets resulting from panel-based approaches.

As sequencing platforms and informatic systems designed to quickly analyze large amounts of genomic data become increasingly agile, and as these testing modalities become increasingly available through commercial means, the likelihood that institutions will transition toward genomic sequencing as a first-line genetic testing strategy continues to increase. As such, our resolve to tackle and mitigate the ethical concerns that accompany these testing modalities must continue to strengthen as well.

\section{Conclusions}

This paper reviewed select ethical aspects regarding the use of ES and GS in NBS and in the diagnostic evaluation of critically ill newborns (please see the Bush, Al-Hertani and Bodamer article in this Special Issue for the broader scope and further discussion). The clinical utility and cost-effectiveness of NGS-based NBS are yet to be established. Dr. Francis Collins, NIH Director, has remarked: “ . . whether you like it or not, a complete sequencing of newborns is not far away" [44]. Genomic sequencing has caused a paradigm shift in the diagnosis of orphan diseases and will inevitably become a part of newborn screening in the near future. Yet, communities of medical geneticists, neonatologists, molecular geneticists and policymakers need to come together as a team to carefully analyze the findings of the pilot studies and improve on the shortcomings of the technique before this can become a reality. In the critically ill population, despite the potential pitfalls, multiple studies have demonstrated that both clinicians and parents have overwhelmingly positive impressions of the impact of rapid genomic sequencing in the ICU setting, regardless of whether the result returned was diagnostic [45-47].

Author Contributions: Conceptualization, A.L.G. and J.H.; methodology, K.S. and J.H.; software, N/A; validation, N/A formal analysis, K.S. and J.H.; investigation, K.S. and J.H.; resources, K.S. and J.H.; data curation, K.S. and J.H.; writing-original draft preparation, K.S. and J.H.; writingreview and editing, K.S., A.L.G. and J.H.; visualization, K.S. and J.H.; supervision, A.L.G.; project administration, A.L.G.; funding acquisition, A.L.G. All authors have read and agreed to the published version of the manuscript.

Funding: This research received no external funding.

Conflicts of Interest: The authors declare no conflict of interest.

\section{References}

1. Roman, T.S.; Crowley, S.B.; Roche, M.I.; Foreman, A.K.M.; O’Daniel, J.M.; Seifert, B.A.; Lee, K.; Brandt, A.; Gustafson, C.; DeCristo, D.M.; et al. Genomic Sequencing for Newborn Screening: Results of the NC NEXUS Project. Am. J. Hum. Genet. 2020, 107, 596-611. [CrossRef]

2. Holm, I.A.; Agrawal, P.B.; Ceyhan-Birsoy, O.; Christensen, K.D.; Fayer, S.; Frankel, L.A.; Genetti, C.A.; Krier, J.B.; LaMay, R.C.; Levy, H.L.; et al. The BabySeq project: Implementing genomic sequencing in newborns. BMC Pediatr. 2018, 18, 225. [CrossRef] [PubMed]

3. Saunders, C.J.; Miller, N.A.; Soden, S.E.; Dinwiddie, D.L.; Noll, A.; Alnadi, N.A.; Andraws, N.; Patterson, M.L.; Krivohlavek, L.A.; Fellis, J.; et al. Rapid whole-genome sequencing for genetic disease diagnosis in neonatal intensive care units. Sci. Transl. Med. 2012, 4, 154ra135. [CrossRef] 
4. Ceyhan-Birsoy, O.; Murry, J.B.; Machini, K.; Lebo, M.S.; Yu, T.W.; Fayer, S.; Genetti, C.A.; Schwartz, T.S.; Agrawal, P.B.; Parad, R.B.; et al. Interpretation of Genomic Sequencing Results in Healthy and Ill Newborns: Results from the BabySeq Project. Am. J. Hum. Genet. 2019, 104, 76-93. [CrossRef]

5. El-Hattab, A.W.; Almannai, M.; Sutton, V.R. Newborn Screening: History, Current Status, and Future Directions. Pediatr. Clin. N. Am. 2017, 65, 389-405. [CrossRef] [PubMed]

6. Fabie, N.A.V.; Pappas, K.B.; Feldman, G.L. The Current State of Newborn Screening in the United States. Pediatr. Clin. N. Am. 2019, 66, 369-386. [CrossRef] [PubMed]

7. American College of Medical Genetics Newborn Screening Expert Group. Newborn screening: Toward a uniform screening panel and system-executive summary. Pediatrics 2006, 117, S296-S307. [CrossRef]

8. Guthrie, R.; Susi, A. A simple phenylalanine method for detecting phenylketonuria in large populations of newborn infants. Pediatrics 1963, 32, 338-343. [PubMed]

9. Millington, D.S.; Kodo, N.; Norwood, D.L.; Roe, C.R. Tandem mass spectrometry: A new method for acylcarnitine profiling with potential for neonatal screening for inborn errors of metabolism. J. Inherit. Metab. Dis. 1990, 13, 321-324. [CrossRef]

10. Matern, D.; Gavrilov, D.; Oglesbee, D.; Raymond, K.; Rinaldo, P.; Tortorelli, S. Newborn screening for lysosomal storage disorders. Semin. Perinatol. 2015, 39, 206-216. [CrossRef]

11. Wasserstein, M.P.; Andriola, M.; Arnold, G.; Aron, A.; Duffner, P.; Erbe, R.W.; Escolar, M.L.; Estrella, L.; Galvin-Parton, P.; Iglesias, A.; et al. Clinical outcomes of children with abnormal newborn screening results for Krabbe disease in New York State. Genet. Med. 2016, 18, 1235-1243. [CrossRef]

12. Kemper, A.R.; Brosco, J.; Comeau, A.M.; Green, N.; Grosse, S.D.; Jones, E.; Kwon, J.M.; Lam, W.K.; Ojodu, J.; Prosser, L.A.; et al. Newborn screening for X-linked adrenoleukodystrophy: Evidence summary and advisory committee recommendation. Genet. Med. 2016, 19, 121-126. [CrossRef]

13. Boardman, F.K.; Young, P.J.; Griffiths, F.E. Newborn screening for spinal muscular atrophy: The views of affected families and adults. Am. J. Med. Genet. A 2017, 173, 1546-1561. [CrossRef]

14. Botkin, J.R.; Rothwell, E. Whole Genome Sequencing and Newborn Screening. Curr. Genet. Med. Rep. 2016, 4, 1-6. [CrossRef]

15. Hall, P.L.; Li, H.; Hagar, A.F.; Jerris, S.C.; Wittenauer, A.; Wilcox, W. Newborn Screening for X-Linked Adrenoleukodystrophy in Georgia: Experiences from a Pilot Study Screening of 51,081 Newborns. Int. J. Neonatal. Screen. 2020, 6, 81. [CrossRef] [PubMed]

16. Vasquez-Loarte, T.; Thompson, J.D.; Merritt, J.L., 2nd. Considering Proximal Urea Cycle Disorders in Expanded Newborn Screening. Int. J. Neonatal. Screen. 2020, 6, 77. [CrossRef]

17. Peretz, R.H.; Mew, N.A.; Vernon, H.J.; Ganetzky, R.D. Prospective diagnosis of MT-ATP6-related mitochondrial disease by newborn screening. Mol. Genet. Metab. 2021, 134, 37-42. [CrossRef]

18. Wilson, J.; Jungner, J. Principles and Practices of Screening for Disease; Public Health Papers; World Health Organization: Geneva, Switzerland, 1968; p. 34 .

19. Adhikari, A.N.; Gallagher, R.C.; Wang, Y.; Currier, R.J.; Amatuni, G.; Bassaganyas, L.; Chen, F.; Kundu, K.; Kvale, M.; Mooney, S.D.; et al. The role of exome sequencing in newborn screening for inborn errors of metabolism. Nat. Med. 2020, 26, 1392-1397. [CrossRef] [PubMed]

20. Wojcik, M.H.; Zhang, T.; Ceyhan-Birsoy, O.; Genetti, C.A.; Lebo, M.S.; Yu, T.W.; Parad, R.B.; Holm, I.A.; Rehm, H.L.; Beggs, A.H.; et al. Discordant results between conventional newborn screening and genomic sequencing in the BabySeq Project. Genet. Med. 2021, 23, 1372-1375. [CrossRef]

21. Friedman, J.M.; Cornel, M.C.; Goldenberg, A.J.; Lister, K.J.; Sénécal, K.; Vears, D.F.; Global Alliance for Genomics and Health Regulatory and Ethics Working Group Paediatric Task Team. Genomic newborn screening: Public health policy considerations and recommendations. BMC Med. Genom. 2017, 10, 9. [CrossRef] [PubMed]

22. Tarini, B.A.; Goldenberg, A.J. Ethical issues with newborn screening in the genomics era. Annu. Rev. Genom. Hum. Genet. 2012, 13, 381-393. [CrossRef] [PubMed]

23. Ross, L.F.; Saal, H.M.; David, K.L.; Anderson, R.R.; American Academy of Pediatrics; American College of Medical Genetics and Genomics. Technical report: Ethical and policy issues in genetic testing and screening of children. Genet. Med. 2013, 15, 234-245. [CrossRef]

24. Reinstein, E. Challenges of using next generation sequencing in newborn screening. Genet. Res. 2015, 97, e21. [CrossRef] [PubMed]

25. Kingsmore, S.F.; Henderson, A.; Owen, M.J.; Clark, M.M.; Hansen, C.; Dimmock, D.; Chambers, C.D.; Jeliffe-Pawlowski, L.L.; Hobbs, C. Measurement of genetic diseases as a cause of mortality in infants receiving whole genome sequencing. NPJ Genom. Med. 2020, 5, 49. [CrossRef] [PubMed]

26. Weiner, J.; Sharma, J.; Lantos, J.; Kilbride, H. How infants die in the neonatal intensive care unit: Trends from 1999 through 2008. Arch. Pediatr. Adolesc. Med. 2011, 165, 630-634. [CrossRef] [PubMed]

27. Berg, J.S.; Agrawal, P.B.; Bailey, D.B.; Beggs, A.H.; Brenner, S.E.; Brower, A.M.; Cakici, J.A.; Ceyhan-Birsoy, O.; Chan, K.; Chen, F.; et al. Newborn Sequencing in Genomic Medicine and Public Health. Pediatrics 2017, 139, e20162252. [CrossRef]

28. Willig, L.K.; Petrikin, J.E.; Smith, L.D.; Saunders, C.J.; Thiffault, I.; Miller, N.A.; Soden, S.E.; Cakici, J.A.; Herd, S.M.; Twist, G.; et al. Whole-genome sequencing for identification of Mendelian disorders in critically ill infants: A retrospective analysis of diagnostic and clinical findings. Lancet Respir. Med. 2015, 3, 377-387. [CrossRef] 
29. Van Diemen, C.C.; Kerstjens-Frederikse, W.S.; Bergman, K.A.; De Koning, T.J.; Sikkema-Raddatz, B.; Van Der Velde, J.K.; Abbott, K.M.; Herkert, J.C.; Löhner, K.; Rump, P.; et al. Rapid Targeted Genomics in Critically Ill Newborns. Pediatrics 2017, 140, e20162854. [CrossRef]

30. Meng, L.; Pammi, M.; Saronwala, A.; Magoulas, P.; Ghazi, A.R.; Vetrini, F.; Zhang, J.; He, W.; Dharmadhikari, A.V.; Qu, C.; et al. Use of Exome Sequencing for Infants in Intensive Care Units: Ascertainment of Severe Single-Gene Disorders and Effect on Medical Management. JAMA Pediatr. 2017, 171, e173438. [CrossRef]

31. French, C.E.; Delon, I.; Dolling, H.; Sanchis-Juan, A.; Shamardina, O.; Mégy, K.; Abbs, S.; Austin, T.; Bowdin, S.; Branco, R.G.; et al. Whole genome sequencing reveals that genetic conditions are frequent in intensively ill children. Intensive Care Med. 2019, 45, 627-636. [CrossRef]

32. Elliott, A.M.; du Souich, C.; Lehman, A.; Guella, I.; Evans, D.M.; Candido, T.; Tooman, L.; Armstrong, L.; Clarke, L.; Gibson, W.; et al. RAPIDOMICS: Rapid genome-wide sequencing in a neonatal intensive care unit-Successes and challenges. Eur. J. Pediatr. 2019, 178, 1207-1218. [CrossRef] [PubMed]

33. Kingsmore, S.F.; Cakici, J.A.; Clark, M.M.; Gaughran, M.; Feddock, M.; Batalov, S.; Bainbridge, M.N.; Carroll, J.; Caylor, S.A.; Clarke, C.; et al. A Randomized, Controlled Trial of the Analytic and Diagnostic Performance of Singleton and Trio, Rapid Genome and Exome Sequencing in Ill Infants. Am. J. Hum. Genet. 2019, 105, 719-733. [CrossRef] [PubMed]

34. Freed, A.S.; Clowes Candadai, S.V.; Sikes, M.C.; Thies, J.; Byers, H.M.; Dines, J.N.; Ndugga-Kabuye, M.K.; Smith, M.B.; Fogus, K.; Mefford, H.C.; et al. The Impact of Rapid Exome Sequencing on Medical Management of Critically Ill Children. J. Pediatr. 2020, 226, 202-212.e1. [CrossRef] [PubMed]

35. Farnaes, L.; Hildreth, A.; Sweeney, N.M.; Clark, M.M.; Chowdhury, S.; Nahas, S.; Cakici, J.A.; Benson, W.; Kaplan, R.H.; Kronick, R.; et al. Rapid whole-genome sequencing decreases infant morbidity and cost of hospitalization. NPJ Genom. Med. 2018, 3, 10. [CrossRef]

36. Kernohan, K.D.; Hartley, T.; Naumenko, S.; Armour, C.M.; Graham, G.E.; Nikkel, S.M.; Lines, M.; Geraghty, M.T.; Richer, J.; Mears, W.; et al. Diagnostic clarity of exome sequencing following negative comprehensive panel testing in the neonatal intensive care unit. Am. J. Med. Genet. A 2018, 176, 1688-1691. [CrossRef] [PubMed]

37. Kingsmore, S.F. Is Rapid Exome Sequencing Standard of Care in the Neonatal and Pediatric Intensive Care Units? J. Pediatr. 2020, 226, 14-15. [CrossRef] [PubMed]

38. Ross, L.F.; Clayton, E.W. Ethical Issues in Newborn Sequencing Research: The Case Study of BabySeq. Pediatrics 2019, 144, e20191031. [CrossRef]

39. Bunnik, E.M.; de Jong, A.; Nijsingh, N.; de Wert, G.M.W.R. The New Genetics and Informed Consent: Differentiating Choice to Preserve Autonomy: The New Genetics and Informed Consent: Differentiating Choice to Preserve Autonomy. Bioethics 2013, 27, 348-355. [CrossRef]

40. Holm, I.A.; McGuire, A.; Pereira, S.; Rehm, H.; Green, R.C.; Beggs, A.H.; BabySeq Project Team. Returning a Genomic Result for an Adult-Onset Condition to the Parents of a Newborn: Insights from the BabySeq Project. Pediatrics 2019, 143, S37-S43. [CrossRef]

41. Van der Meer, L.; van Duijn, E.; Wolterbeek, R.; Tibben, A. Adverse childhood experiences of persons at risk for Huntington's disease or BRCA1/2 hereditary breast/ovarian cancer. Clin. Genet. 2012, 81, 18-23. [CrossRef]

42. Brunelli, L.; Jenkins, S.M.; Gudgeon, J.M.; Bleyl, S.B.; Miller, C.E.; Tvrdik, T.; Dames, S.A.; Ostrander, B.; Daboub, J.A.F.; Zielinski, B.A.; et al. Targeted gene panel sequencing for the rapid diagnosis of acutely ill infants. Mol. Genet. Genom. Med. 2019, 7, e00796. [CrossRef] [PubMed]

43. Maron, J.L.; Kingsmore, S.F.; Wigby, K.; Chowdhury, S.; Dimmock, D.; Poindexter, B.; Suhrie, K.; Vockley, J.; Diacovo, T.; Gelb, B.D.; et al. Novel Variant Findings and Challenges Associated with the Clinical Integration of Genomic Testing: An Interim Report of the Genomic Medicine for Ill Neonates and Infants (GEMINI) Study. JAMA Pediatr. 2021, 175, e205906. [CrossRef]

44. Elroy, M. Researchers and Policymakers Point to Successes and Challenges in Personalized Medicine; American Association for the Advancement of Science (AAAS): Washington, DC, USA, 2009.

45. Dimmock, D.P.; Clark, M.M.; Gaughran, M.; Cakici, J.A.; Caylor, S.A.; Clarke, C.; Feddock, M.; Chowdhury, S.; Salz, L.; Cheung, C.; et al. An RCT of Rapid Genomic Sequencing among Seriously Ill Infants Results in High Clinical Utility, Changes in Management, and Low Perceived Harm. Am. J. Hum. Genet. 2020, 107, 942-952. [CrossRef] [PubMed]

46. Cakici, J.A.; Dimmock, D.P.; Caylor, S.A.; Gaughran, M.; Clarke, C.; Triplett, C.; Clark, M.M.; Kingsmore, S.F.; Bloss, C.S. A Prospective Study of Parental Perceptions of Rapid Whole-Genome and -Exome Sequencing among Seriously Ill Infants. Am. J. Hum. Genet. 2020, 107, 953-962. [CrossRef] [PubMed]

47. Australian Genomics Health Alliance Acute Care Flagship; Lunke, S.; Eggers, S.; Wilson, M.; Patel, C.; Barnett, C.P.; Pinner, J.; Sandaradura, S.A.; Buckley, M.F.; Krzesinski, E.I.; et al. Feasibility of Ultra-Rapid Exome Sequencing in Critically Ill Infants and Children with Suspected Monogenic Conditions in the Australian Public Health Care System. JAMA 2020, 323, $2503-2511$. 